\title{
A Date Palm Stone Ileal Perforation Discovered During Treatment of a Strangulated Umbilical Hernia
}

\author{
Fofana Naby, Kondano Saa Yawo, Mamy Gnan Francis, Oulare Ibrahima, \\ Soumaoro Labile Togba ${ }^{*}$, Fofana Houssein, Toure Aboubacar, Diallo Aissatou Taran \\ Department of General Surgery, Ignace Deen National Hospital, Conakry, Guinea
}

Email address:

soumaoro66@gmail.com (S. L. Togba)

${ }^{*}$ Corresponding author

To cite this article:

Fofana Naby, Kondano Saa Yawo, Mamy Gnan Francis, Oulare Ibrahima, Soumaoro Labile Togba, Fofana Houssein, Toure Aboubacar, Diallo Aissatou Taran. A Date Palm Stone Ileal Perforation Discovered During Treatment of a Strangulated Umbilical Hernia. Journal of Surgery. Vol. 9, No. 5, 2021, pp. 230-232. doi: 10.11648/j.js.20210905.13

Received: August 13, 2021; Accepted: September 3, 2021; Published: September 15, 2021

\begin{abstract}
Ingestion of foreign bodies is a frequent reason for consultation or admission to the emergency room. It is frequently accidental and involves children whose peak age varies between 9 months and three years. Reported cases of intestinal perforation by stone are rare. Herein we report one case of ileal perforation with a date palm stone discovered during the treatment of an emergency strangulated umbilical hernia in a 2-year-old patient. Clinically, there was a painful, irreducible, non-expansive umbilical swelling with coughing and vomiting. The other hernial orifices were free. Temperature was $36^{\circ} \mathrm{C}$, respiratory rate 98 movements per minute, pulse rate 23 beats per minute. Biologically, hemoglobin was $11.4 \mathrm{G} / \mathrm{dl}$, white blood cells were 9 giga/l. The diagnosis of strangulated umbilical hernia was retained. Intraoperatively, we found a small loop incarcerated in the umbilical ring and perforated in two places by a date palm stone. We proceeded with extraction of the stone, resection with both holes, followed by terminal ileo-ileal anastomosis. The postoperative course was simple and no complications were noted after a 2-year follow-up.
\end{abstract}

Keywords: Ingestion, Date Palm Stone, Ileal Perforation, Management

\section{Introduction}

Hernial strangulation is a serious and dreadful complication of hernia. It can occur at any age and unexpectedly. It is characterized by stricture of the hernial contents within the sac and produces an occlusive syndrome [1]. Foreign body ingestion is a frequent reason for consultation or admission to the emergency room. Foreign body ingestion is accidental in $80 \%$ of children aged between 9 months and 3 years [2]. The ingested foreign bodies reported in the literature are very diverse. With the exception of a few projectiles, ingestion is the main route of entry [3]. Cases of ileal perforation caused by a date palm stone are not reported in the literature to our knowledge. We report a case of ileal perforation caused by a date palm stone discovered during surgical treatment of an emergency strangulated umbilical hernia.

\section{Observation}

A 2-year-old patient was admitted in emergency with periumbilical abdominal pain for 3 hours, with no previous history and an up-to-date vaccination record. Clinical examination on admission revealed a painful umbilical swelling, irreducible, non-expansive on coughing; early vomiting. The other hernia orifices were free. Temperature was $36^{\circ} \mathrm{C}$, respiratory rate 98 movements per minute, pulse 23 beats per minute. The abdomen was generally tender; the rest of the examination was within normal limits. Haemoglobin was $11.4 \mathrm{G} / \mathrm{dl}$, white blood cell count 9 giga/l. The diagnosis of strangulated umbilical hernia was retained, after a short resuscitation the patient was taken to the operating room; under general anaesthesia, we made an incision above and below the umbilical ring, the exploration revealed a small loop incarcerated in the umbilical ring and perforated in two places ( $2 \mathrm{~cm}$ between the perforations) by a 
date palm stone (figures 1 and 2). We proceeded with extraction of the stone, ileal resection with both perforations, followed by terminal ileo-ileal anastomosis; control of haemostasis and cure of the hernia by reinforcement of the wall. The postoperative course was simple; bowel transit resumed on the 4th postoperative day, and the patient was discharged on the 7 th day. No complications were noted after a 2-year follow-up.

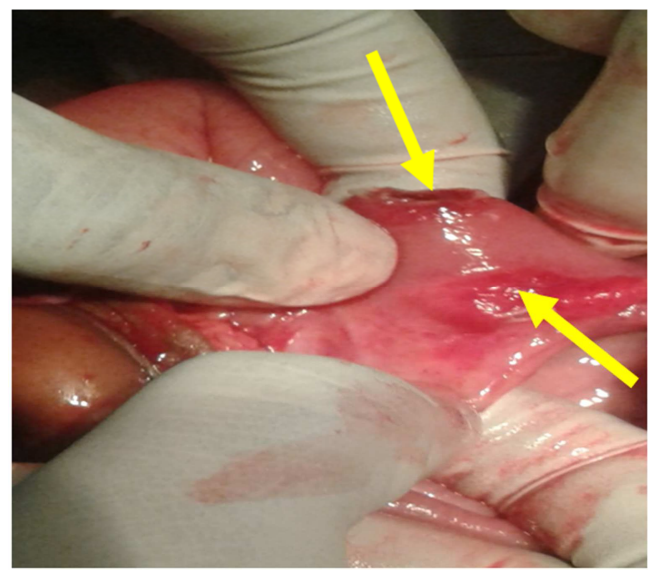

Figure 1. Two ileal perforation (arrow).

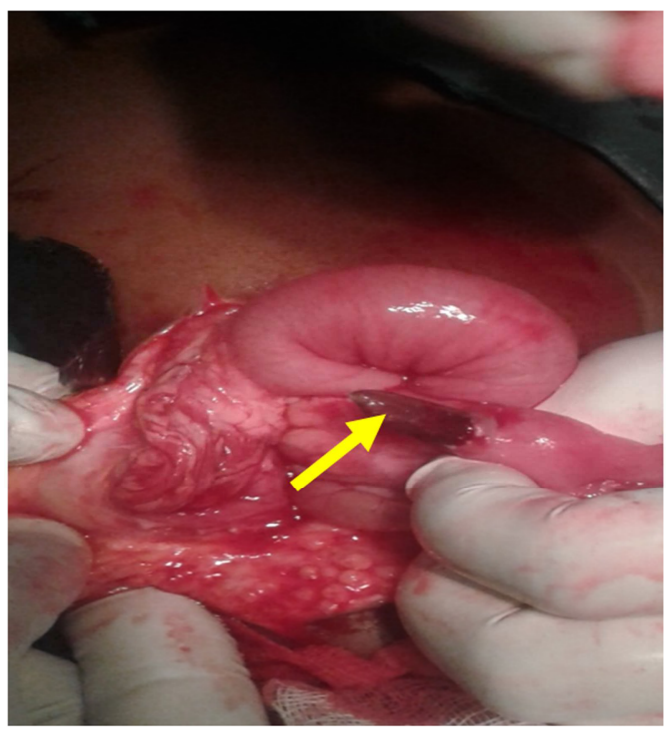

Figure 2. Date palm stone (arrow).

\section{Comments}

The ingestion of foreign bodies is most often accidental and occurs in the paediatric population between the ages of 6 months and 3 years in $70 \%$ of cases and is the most frequent reason for consultation of the emergency department; $10 \%$ of patients are "repeat offenders" [4, 5]. The frequency of ingested foreign bodies is not well known in children [5], with approximately $40 \%$ of cases not being diagnosed because the ingestion is not observed by the parents. The symptoms are the same in children and adults; however, children may remain asymptomatic even in oesophageal locations [6]. The majority of ingested foreign bodies pass through the gastrointestinal tract without clinical signs or complications. However, $10-20 \%$ require endoscopic removal and in less than $1 \%$ surgery is required to reduce the risk of major complications (obstruction, perforation, appendicitis). Because of the non-specificity of the clinic, diagnosis is difficult [7], in only $12 \%$ of cases patients remember swallowing the foreign body and abdominal pain is only found in $70 \%$ of cases [8]. There is no relationship between the clinical signs and the size, shape and vulnancy of the ingested object; the signs may appear progressively several hours after ingestion of the foreign body, or sometimes it is revealed by a complication [9]. Perforation may simulate lower GI haemorrhage, peritonitis, intestinal obstruction, ileitis, appendicitis or may remain asymptomatic, or often be discovered incidentally during laparotomy for other conditions [10]. As foreign bodies are most often radiopaque, standard radiography is often helpful in making the diagnosis and demonstrating signs of hollow organ perforation (radiological pneumoperitoneum). Foreign bodies that are not radiopaque are often diagnosed by CT scan; this allows the location and type of foreign body to be determined [11]. The diagnosis is made by laparotomy in $50 \%$ of cases and the rest by endoscopy (19\%), imaging (14\%) or autopsy (12\%) [12]. Djodjo $M$ et al [13], reported that the physical examination is usually normal and that they noted nonspecific diffuse abdominal pain on clinical examination. The management of these intestinal perforations is well codified. Suturing of the perforation is common in recent perforations, whereas perforations with major peritonitis require bowel resection followed by stoma [14]. Chichom-Mefire A [15], reported that he opted for a suture of the perforation because the perforation was millimetric, the local condition of the small bowel was inflammatory without associated abdominal suppuration and the postoperative course was simple. In $90 \%$ of cases, foreign bodies are not responsible for complications. Beyond the pylorus, however, the presence of an ingested foreign body requires daily clinical and radiological monitoring. Surgery is discussed when there is an absence of progression for 72 hours or when sharp or stinging foreign bodies expose the patient to a risk of perforation. Surgical treatment is required immediately if there is a complication of perforation, haemorrhage or obstruction [16].

\section{Conclusion}

The ingestion of foreign bodies in children is often accidental and asymptomatic; sometimes the complication is indicative of the ingestion of the foreign body. In our context, reducing the risk of foreign body ingestion requires information and education of the population on the dangers of ingested foreign bodies. Surgery intervenes when there is a complication.

\section{Conflict of Interest}

Authors do not have any conflict of interest. 


\section{References}

[1] Weick J, Moore D. (2005) An usual case of umbilical hernia rupture with evisceration. Pediatric surg; 40: 33-35.

[2] Arana A, Hauser B. (2001) Management of ingested foreign bodies in childhood and review of the literature. Eur J Pediatr; 160: 468-72.

[3] Paul G, Buysschaert M, DE Cannière L, Trigaux JP, Donckier J, Coche E. (1991) Abcès du foie et corps étranger appendiculaire. Gastro-entérologie Clinique et Biologique; 15 (10): 762765 .

[4] Eisen GM, Baron TH, Dominitz JA, et al. (2002) Guideline for the management of ingested foreign bodies. Gastrointest Endosc; 55: 802-806.

[5] Michaud L, Bellaiche M, Olives JP. (2009) Ingestion de corps étrangers chez l'enfant. Recommandations du Groupe francophone d'hépatologie, gastroentérologie et nutrition pédiatriques. Arch Pediatr; 16: 54-61.

[6] Haennig A, Bournet B, Jean-Pierre O, Buscail L. (2011) Conduite à tenir devant une ingestion de corps étrangers. Hepato Gastro; 18: 249-257.

[7] Lovece A, Asti E, Andrea Sironi A, et al. (2014) Toothpick ingestion complicated by cecal perforation: case report and literature review. World J Emerg Surg; 9: 63-5.

[8] Su YJ, Lai YC, Chen CC, et al. (2009) Intra-abdominal abscess caused by toothpick injury. Int J Infect Dis; 13 (5): 264-6.

[9] Lheureux P, Cavenaille JC, Cornil A, (1996) Nouvelle M, Sermon F, Leduc D, Arkenasi R. Ingestion de corps étranger: attitude pratique. ReanimUrg; 5: 637-53.

[10] Strain MH, Chisevescu DM, Potopea S. (2011) Successful Endoscopic Treatment of an Unusual Cause of Lower Gastrointestinal Bleeding Using the OVESCO System. J Gastrointestin Liver Dis; 20 (1): 85-7.

[11] Takada M, Kashiwagi R, Sakane M, et al. (2000) 3D-CT diagnosis for ingested foreign bodies. Am J Emerg Med; 18: 192-193.

[12] Sealock RJ, Sabounchi S, Graham DY. (2013) Toothpick Perforation of the Intestines Presenting as Recurrent Abdominal Pain: Possible Roles of Abdominal Ultrasound and MRI. Clin Med Insights Case Rep; 6: 131-5.

[13] Djodjo M, Botti K, Ebouat KMEV, Ohayon P, Yapo-Etté H, Qautrehomme G. (2013) Prise en charge médicale des détenus ayant Ingéré volontairement des corps étrangers: expérience de l'ucsa de la maison d'arrêt de Nice relative à 83 corps étrangers ingérés. Rev Int Sc Méd; 15 (3): 171-177.

[14] Ayaka K, Matsuo S, handa K, et al. (2010) Intestinal Perforation by Ingested Foreign Bodies. Acta medica Nagasaki; 55 (1): 1-5.

[15] Chichom-Mefire A. (2015) Perforation of the splenic flexure of the colon by an ingested wooden toothpick. J Surg Case Rep; 1: 1-2.

[16] Pinero MA, Fernandez Hernandez JA, Carrasco Prats M, et al. (2000) Intestinal perforation by foreign bodies. Eur J Surgery; 166: 307-309. 